$$
\begin{gathered}
\text { エポキシ樹脂／アクリレート系 IPN を } \\
\text { マトリックスとした GFRPの物性 }
\end{gathered}
$$

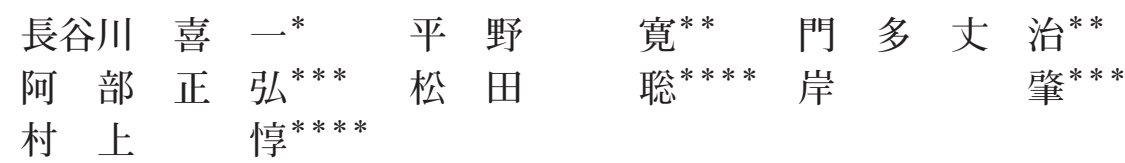

\title{
Properties of GFRP Using Matrix Resin of Epoxy/Acrylate Interpenetrating Polymer Network
}

\author{
by \\ Kiichi Hasegawa ${ }^{*}$, Hiroshi Hirano ${ }^{* *}$, Joji Kadota ${ }^{* *}$, Masahiro Abe***, \\ Satoshi Matsuda ${ }^{* * * *}$, Hajime KIshi ${ }^{* * *}$ and Atsushi Murakami ${ }^{* * * *}$
}

\begin{abstract}
Epoxy resin is used for structural engineering applications such as adhesives and matrix of composite materials. However, epoxy resin have one undesirable property with a poor resistance to crack initiation and growth. Recently many attempts have been made to improve in the fracture toughness of epoxy resin by forming interpenetrating polymer network (IPN) with acrylate. In this study, the mechanical properties and the microscopic structure of Epoxy/Acrylate IPN and its glass fiber reinforced plastics (GFRPs) were investigated. The mode I and II interlaminar fracture toughness $\mathrm{G}_{\mathrm{Ic}}$ and $\mathrm{G}_{\text {IIc }}$ of the GFRP were improved by introducing the IPN into the matrix resin. The shear deformation can be observed on the fracture surface of the epoxy/acrylate matrix composites. The increase in the ductility of the matrix resin would be contributed to the enhancement of the fracture toughness.
\end{abstract}

Key words : Epoxy resin, Acrylate resin, Interpenetrating polymer network (IPN), Glass Fiber reinforced plastic (GFRP), Fracture toughness

\section{1 緒 言}

エポキシ樹脂は，その優れた接着性と機械的性質を生 かして繊維強化プラスチック (FRP) のマトリックス樹脂 として有用である。しかしながら，エポキシ樹脂は一般 に耐衝撃性や強勒性が低く, その改善のため, 各種のエ ラストマーによる変性が行われているが，変性により系 の粘度が高くなり，作業性が低下する欠点がある。我々 は，エポキシ樹脂とジアクリル酸エステルとの相互貫入 高分子網目 (IPN) が, 低粘度でかつ速やかに硬化して, また重合開始剤の選択によって樹脂組成物の構造が制御 できることを明らかにしている.1) 8)本研究では，エポキ シ樹脂/アクリレート系 IPN の動的粘弾性や強勒性につ いて検討すると共に，これをガラス繊維強化プラスチック (GFRP) のマトリックス樹脂として用いた場合の, GFRP の物性に及ぼす影響について検討した。

\section{2 実験}

\section{$2 \cdot 1$ 試料}

エポキシ樹脂は，ビスフェノール $\mathrm{A}$ 型エポキシ樹脂（以

下 DGEBA と略，ジャパンエポキシレジン(㑣製，EPIKOTE 828, エポキシ当量 $=$ 約 191）を, 硬化剮には, ジシア ンジアミド (以下 DICY と略, ジャパンエポキシレジン

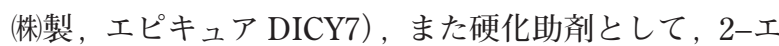
チル-4-メチルイミダゾール (2E4MZ，四国化成工業㑣) 製）を使用した。アクリレートはポリエチレングリコール ジアクリレート（以下 PEGDA と略, 共栄社化学(㑣製, ライトアクリレート 4EG-A： $M_{n}=$ 約 200）を用い, PEGDA のラジカル重合開始剤として, 過酸化ベンゾイル（BPO, 試薬 1 級品）を用いた。用いた試料の構造式を Fig. 1 に 示す。

\section{$2 \cdot 2$ 試験片の作製}

DGEBA と PEGDA を $80 ： 20$ 割合で混合し，そこに DICY を混合樹脂 100 部に対して 3.2 部, 硬化促進剤で ある $2 \mathrm{E} 4 \mathrm{MZ}$ を 0.8 部，ラジカル重合開始剤である $\mathrm{BPO}$ を 0.3 部加えて, 減圧下で 30 分間さらに擋找して反応混 合物を作製した。この反応混合物をあらかじめ $160^{\circ} \mathrm{C} に$ 加熱した金型（試験片寸法： $100 \times 10 \times 4 \mathrm{~mm}$ ）に注型し て, $160^{\circ} \mathrm{C} て ゙ 2$ 時間, $180^{\circ} \mathrm{C} て ゙ 4$ 時間硬化して短冊状の試 験片を作製した。GFRP は厚み $200 \mu \mathrm{m}$, 目付 $210 \mathrm{~g} / \mathrm{m}^{2}$ のガラスクロス（3-アミアプロピルトリメトキシシラン 処理，新神戸電機㑣提供）を使用し，上記の樹脂配合物 を含浸後, $140^{\circ} \mathrm{C}, 10$ 分間反応させてプリプレグを作成 し，24層積み重ね，真空プレスを用いて成形した。硬化

\footnotetext{
$\dagger \quad$ 原稿受理 平成 18 年 4 月 24 日 Received Apr. 24, 2006 @ 2007 The Society of Materials Science, Japan

* 正 会員 大阪市立工業研究所 † 536-8553 大阪市城東区森之宮, Osaka Municipal Technical Res. Inst., Joto-ku, Osaka, 536-8553

**大阪市立工業研究所 于536-8553 大阪市城東区森之宮, Osaka Municipal Technical Res. Inst., Joto-ku, Osaka, 536-8553

*** 兵庫県立大学大学院工学研究科７671-2201 姫路市書写, Graduate School of Eng., Hyogo Univ., Shosha, Himeji, 671-2201

**** 正 会 員 兵庫県立大学大学院工学研究科 †671-2201 姫路市書写, Graduate School of Eng., Hyogo Univ., Shosha, Himeji, 671-2201
} 


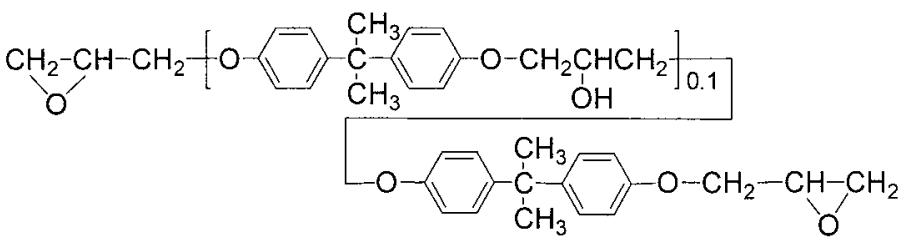

\section{DGEBA}

$\mathrm{H}_{2} \mathrm{~N}-\underset{11}{\mathrm{C}}-\mathrm{NH} \mathrm{CN}$

DICY
2E4MZ<smiles>Cc1c[nH]c(CCC(=O)OC(=O)c2ccccc2)n1</smiles>

$\mathrm{CH}_{2}=\mathrm{CH}-\underset{\mathrm{O}}{\mathrm{C}}+\mathrm{OCH}_{2} \mathrm{CH}_{2}+\mathrm{n}-\underset{\mathrm{O}}{\mathrm{O}}-\mathrm{CH}=\mathrm{CH}_{2}$

PEDGA

Fig. 1 Chemical structures of epoxy resin, acrylate and curing agents.

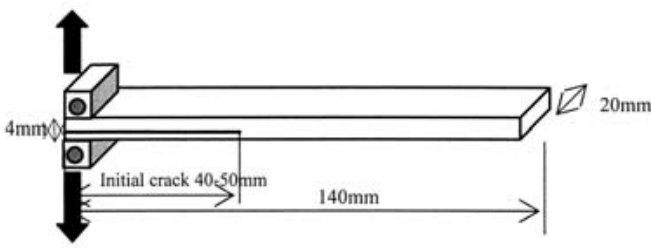

Fig. 2 Description of Double Cantilever Beam Test.

条件は $160^{\circ} \mathrm{C} て ゙ 2$ 時間， $180^{\circ} \mathrm{C} て ゙ ~ 4$ 時間とした. GFRP の ガラス繊維含量は 58 重量\%であった。なお，DGEBA と PEGDAの比は 1：1に近いほど，IPN としての特徴が明 確になると考えられるが，DGEBA/PEGDA 比が 70/30 以 下では硬化物の Tg が金型温度より低くなり，GFRPの離 型が困難となったため, 本研究では, 硬化物の $\mathrm{Tg}$ が $160^{\circ} \mathrm{C}$ 以上を示す DGEBA/PEGDA (80/20) 系を用いた。

\section{$2 \cdot 3$ 物性測定}

得られた硬化物は，SEM 観察（日本電子(株)製，JSM5400)，動的粘弾性測定（セイコーインスッルメンツ(株) 社製，DMS-200，つかみ具距離 $20 \mathrm{~mm}$ ，周波数 $1 \mathrm{~Hz}$ ，昇 温速度 $2^{\circ} \mathrm{C} /$ 分，曲げモード)，破壊靶性 $\left(\mathrm{K}_{\mathrm{Ic}}\right)$ 試験 (ASTM 5045, 支点間距離 $40 \mathrm{~mm}$, 試験速度 $10 \mathrm{~mm} /$ 分, 3 点曲げ）および層間破壊勒性試験（JISK7086）を行っ た。層間破壊勒性試験は双片持ち梁 (Double Cantilever Beam) 試験による $\mathrm{G}_{\mathrm{Ic}}$ と端面切欠き曲げ (End Notched Flexure) 試験による $\mathrm{G}_{\text {IIc }}$ を求めた。それぞれの試験の概 略図を Fig. 2 と Fig. 3 に示す。

\section{$3 \cdot 1$ 動的粘弾性}

\section{3 結 果と考 察}

樹脂単独硬化物の動的粘弾性測定結果を Fig. 4 に示 した。エポキシ樹脂単独系の場合 $\tan \delta$ は $187^{\circ} \mathrm{C}$ に一の ピークを示している。一方, エポキシ樹脂/アクリレート IPN 系では，高温側と低温側の 2 つの幅広くなったピー クが見られ，エポキシ樹脂リッチ相とアクリレートリッチ 相とに部分相分離していると考えられる。高温側のピー クはエポキシ樹脂リッチ相の $\mathrm{Tg}$ を示しているが，若干， 低温側にシフトしている。

Fig. 5 に GFRP の動的粘弾性測定結果を示した. Fig. 4 に比べ貯蔵弾性率はほほ 1 桁大きくなっている。また，

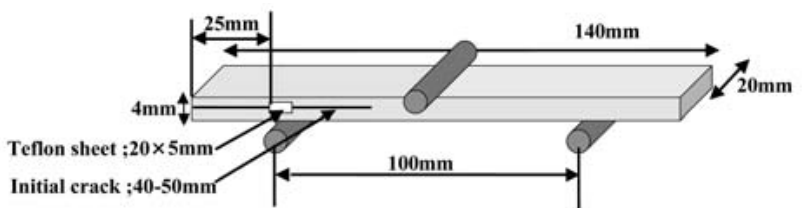

Fig. 3 Description of End Notched Flexure Test.

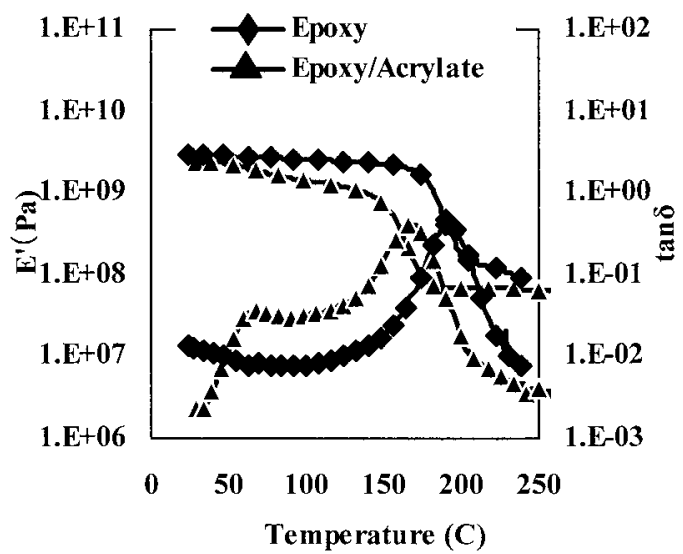

Fig. 4 Dynamic mechanical analysis of cured epoxy resin and cured epoxy/acrylate IPN.

$\tan \delta$ のピーク高さが小さくなっており，ガラス繊維の強 化効果が現れている。さらにエポキシ樹脂／アクリレー ト IPN 系では，高温側ピークが低温側にシフトし，低温 側のアクリレート相のピークが不明確となっている。つ まり GFRPの方が，相溶化が進行した IPN になっている ことが分かる。この原因として，用いたガラス繊維の表面 処理剤であるアミノシランがエポキシ樹脂とアクリレート の相溶性を高めたためではないかと考えている。すなわ ち，本研究で用いた系では，エポキシ樹脂はイミダゾー 儿触媒による開環重合，アクリレートは過酸化物による ラジカル重合によりそれぞれ単独架橋構造をとり，それ が絡み合って IPN 構造を形成すると考えているが，そこ にアミンが介在すると，エポキシ基とアミンの付加反応， アクリレート基とアミンのマイケル付加反応が扢こり， 一部共重合組成が生成し，両架橋系の相溶性が高くなる ことが推定される．Fig. 6 にガラス䋊維近傍での SEM 


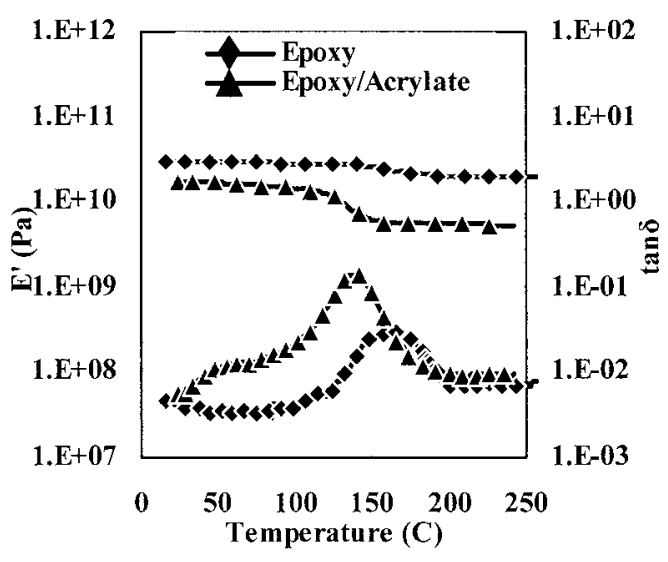

Fig. 5 Dynamic mechanical analysis of GFRP of epoxy resin and epoxy/acrylate IPN.

写真を示す。アクリレートに由来する粒子がほとんど見 られず，相溶性が高くなっていることが分かる.

\section{$3 \cdot 2$ 破壊靶性}

樹脂単独硬化系の破壊勒性試験の結果を Fig. 7 に示 した。エポキシ樹脂単独系に比べ，エポキシ樹脂／アク リレート IPN 系の $\mathrm{K}_{\mathrm{Ic}}$ は約 $50 \%$ 大きくなっている。これ は柔軟なアクリレート架橋体の導入による IPN が塑性変 形し易くなったことと，一部相分離したアクリレート粒 子がクラック進展を妨害したためと考えられる。これを

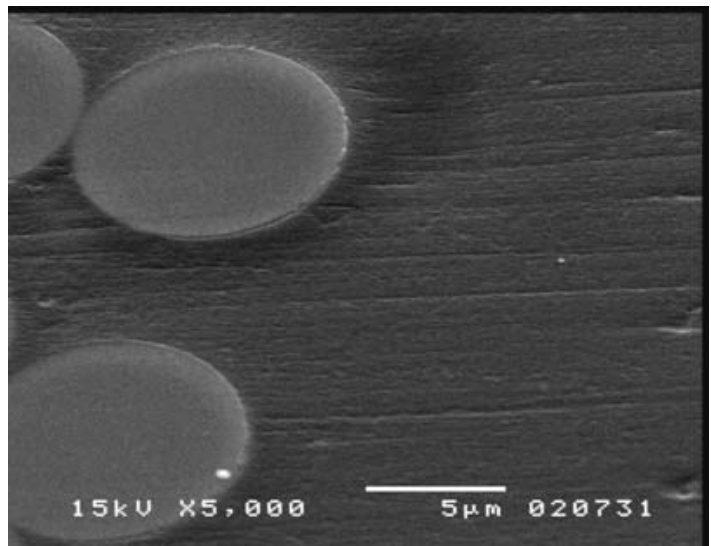

Fig. 6 SEM photo of cross section of GFRP using epoxy/acrylate IPN matrix.

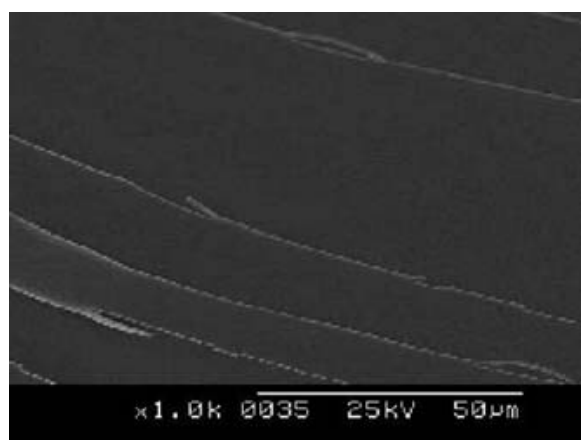

(a)
確認するために破断面の SEM 観察を行った結果を Fig. 8 に示す。エポキシ樹脂単独硬化系ではスムーズな面となっ ているが, IPN 系では相分離構造が見られる.

次に, GFRP の層間破壊勒性を評価するために，両片 持ち梁試験（DCB 試験，モード I, G IC ) と端面切り欠 き曲げ試験（ENF 試験，モード II， G IIC）を行った結果 を Fig. 9 と 10 に示した. Fig. 9 には樹脂単独系の結果 も合わせて示す。この図より，樹脂単独系の GIC が IPN 化により大きく向上していることが分かる. GFRP の場 合は単独系ほど向上程度は大きくないが，約 15\%の増加 を示している。

Fig. 10 に打いても，Fig. 9 と同様にIPN 化により層 間破壊勒性值が向上していることが分かる。

Fig. 11 にGFRP の DCB 試験後の, 破面の SEM 写真 を示す。上段は低倍率の写真で，下段はその一部を高倍 率で撮影したものである。クラックは左から右へ進展し ている。段の写真で凹凸のないマトリックス部分の様 子を見ると，(b) のIPN 系の方が荒机て抢り，マトリッ クスの塑性変形により，クラックの進展を妨げているこ とが分かる。下段の写真はガラス繊維部分を特に拡大し

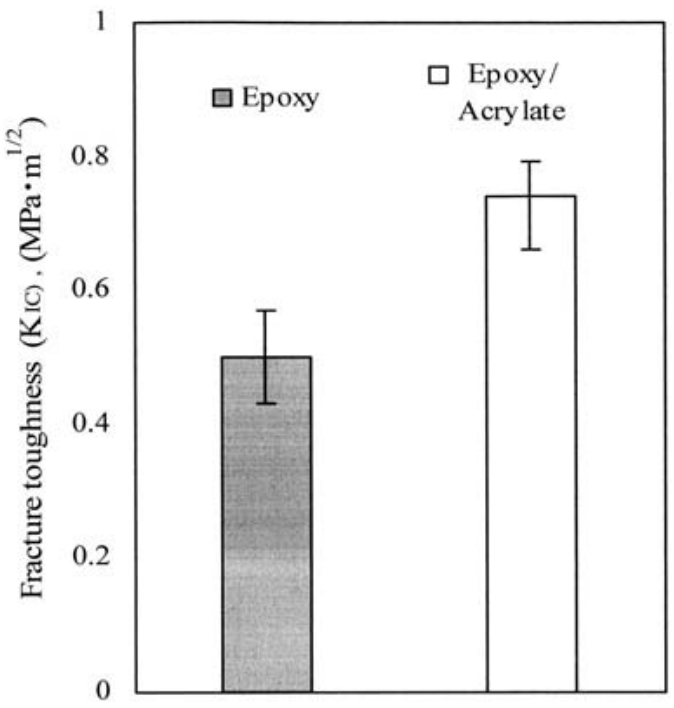

Fig. 7 Fracture toughness $\left(\mathrm{K}_{\mathrm{Ic}}\right)$ of cured epoxy resin and cured epoxy/acrylate IPN.

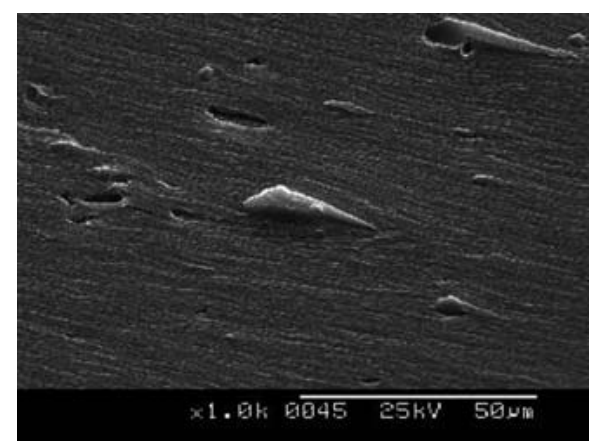

(b)

Fig. 8 SEM photos of fracture surface of cured epoxy resin and cured epoxy/acrylate IPN ; (a) epoxy resin, (b) epoxy/acrylate IPN. 

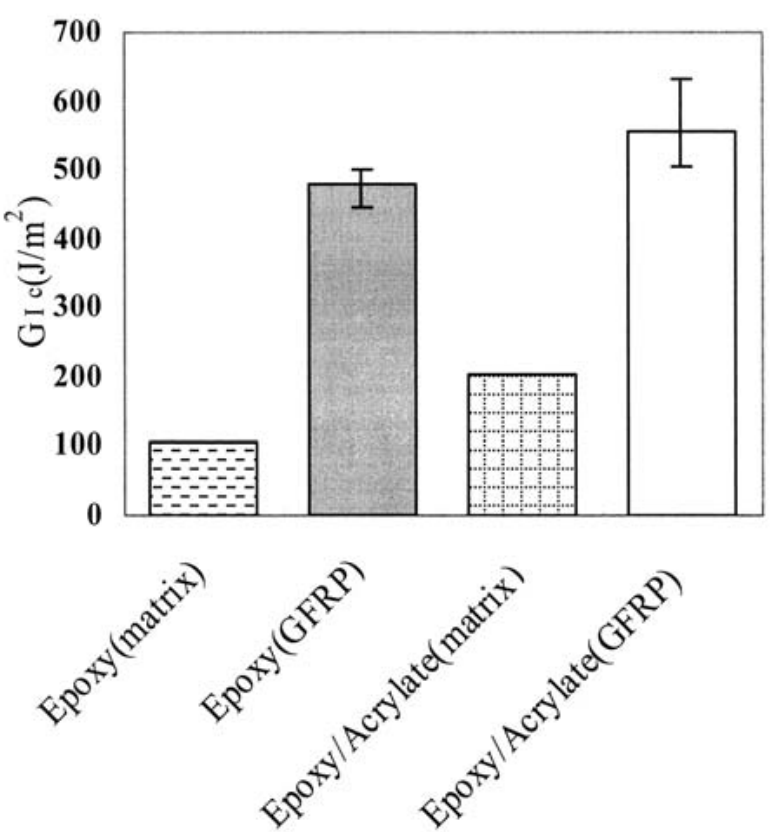

Fig. 9 Fracture toughness $\left(\mathrm{G}_{\mathrm{Ic}}\right)$ of cured epoxy resin, cured epoxy/acrylare IPN, and GFRPs using these matrix resins.

たものだが，エポキシ単独系（a）の場合，ガラス繊維の 表面が比較的なめらかであり, ガラス繊維表面で界面剥 離が打こっていると考えられる。一方，IPN 系 (b) では ガラス表面に樹脂が付着しており, 界面接着力が大きい ことが分かる．以上のことから，IPN 系 GFRP の場合，
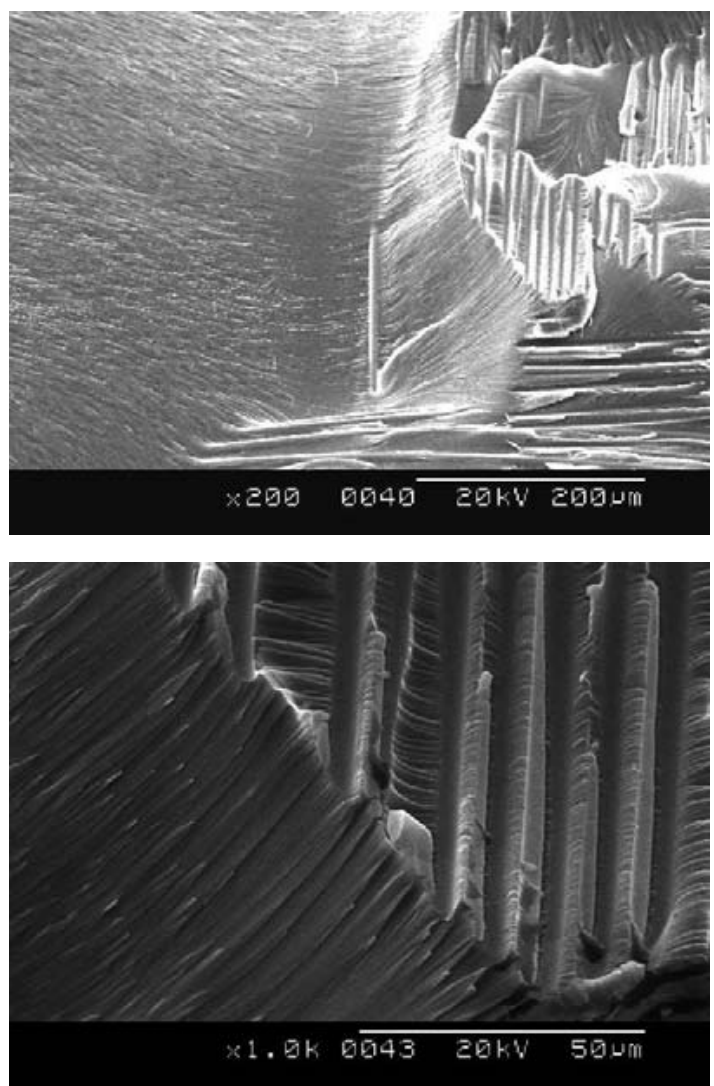

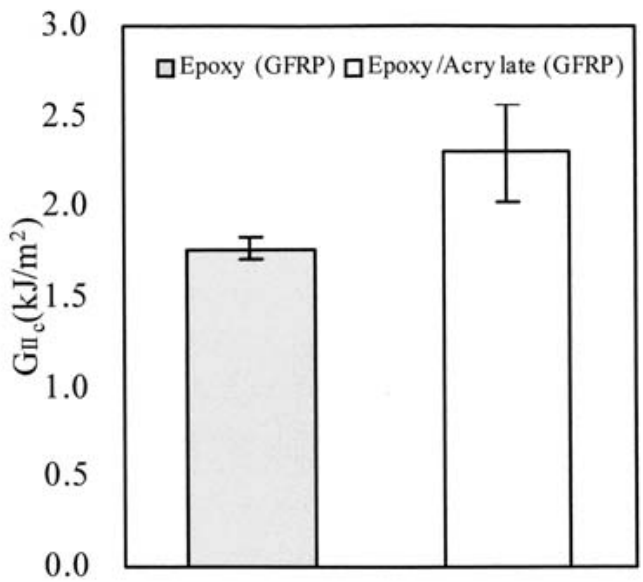

Fig. 10 Fracture toughness (GIIC) of GFRPS using matrix of epoxy resin and epoxy/acrylare IPN.

マトリックス自体の塑性変形し易さと，ガラス繊維との 良好な界面接着力が層間破壊勒性值の向上をもたらした ものと考えられる。

$$
4 \text { 結 論 }
$$

エポキシ樹脂の強勒化を向上させるために，エポキシ 樹脂／アクリレート系 IPN 硬化物の物性について検討し た。その結果，IPN 化により，耐熱性は若干低下するが, 強勒性が向上することが分かった。ささらに，このIPN 系 をガラス繊維強化プラスチック (GFRP) のマトリックス 樹脂として用いたところ，エポキシ樹脂単独系に比べ, 層間破壊勒性の向上がみられた。これは，IPN 系マトリ
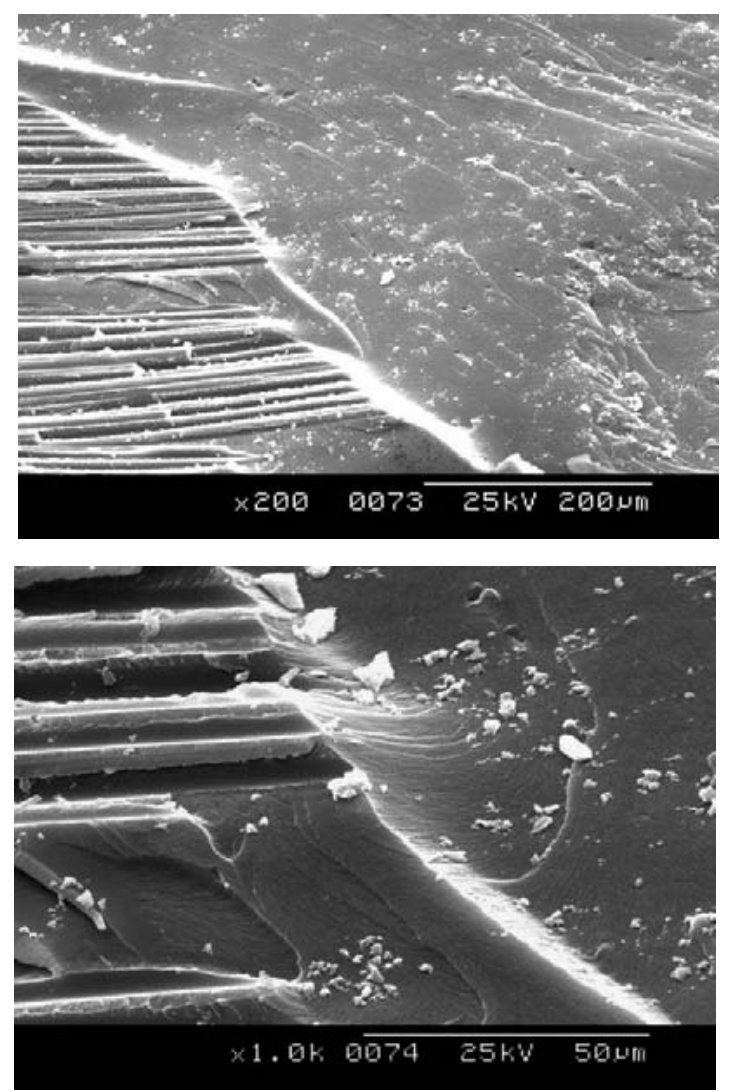

Fig. 11 SEM photos of interlaminar fracture surface of DCB test pieces for GFRP using epoxy resin and epoxy/acrylate IPN ; (a) matrix : epoxy resin, (b) matrix : epoxy/acrylate IPN. 
ックス樹脂の塑性変形性とガラス繊維界面での接着性の 良さによるものと結論した。

\section{参 考 文 献}

1) K. Hasegawa, A. Fukuda and K. Uede, "Study of Acrylatemodified Epoxy Resin (1) : Relation between Composition and Curing Behavior of Acrylate-modified Epoxy Resin”, Kagaku To Kogyo (Osaka), Vol.65, No.8, pp.351-354 (1991).

2 ) K. Hasegawa, A. Fukuda, T. Kurohara and K. Uede, "Study of Acrylate-modified Epoxy Resin (2) : The Effect of Curing Processes on Properties of Cured Resin”, Kagaku To Kogyo (Osaka), Vol.67, No.3, pp.117-122 (1993).

3 ) K. Hasegawa, A. Matsumoto, K. Otsuka, A. Fukuda, A. Kaji and S. Yamada, "Study of Acrylate-modified Epoxy Resin (3) : Properties of Glass Fiber Reinforced Epoxy Resin”, Kagaku To Kogyo (Osaka), Vol.69, No.3, pp.116-119 (1995).

4 ) K. Hasegawa, A. Matsumoto, K. Otsuka and A. Fukuda, "Study of Acrylate-modified Epoxy Resin (4) : Properties and Curing Behavior of Catalyst-Curing System”, Kagaku To Kogyo (Osaka), Vol.70, No.3, pp.115-122 (1996).
5 ) K. Hasegawa, A. Matsumoto, K. Otsuka and A. Fukuda, "Study of Acrylate-modified Epoxy Resin (5) : Molding and Properties of Hybridized Thermosetting Resin/Thermoplastic Resin Composites”, Kagaku To Kogyo (Osaka), Vol.70 No.9, pp.378-383 (1996).

$6)$ H. Okumura, M. Okoshi, K. Hasegawa and J. Kadota, "Mechanical properties of Acrylate-modified Epoxy resin : Imidazole-cured epoxy system”, Journal of Network Polymer, Japan, Vol.24, No.2, pp.104-111 (2003).

7 ) H. Okumura, M. Okoshi, K. Hasegawa and J. Kadota, "Microstructures of Acrylate-modified Epoxy Resin Cured with Acid Anhydride”, Journal of Network Polymer, Japan, Vol.24, No.3, pp.148-155 (2003).

$8)$ H. Okumura, Y. Takeoka, K. Hasegawa and J. Kadota, "Mechanical Properties of Epoxy/Acrylate IPN System Cured with Phthalic Anhydride”, Journal of Network Polymer, Japan, Vol.25, No.2, pp.60-61 (2004). 